\title{
Picking up good vibrations: Discrepant vibrator use, sexual functioning, and sexual well-being in women with male partners
}

\section{S. Gauvin, L. Yessick \& C. F. Pukall}

To cite this article: S. Gauvin, L. Yessick \& C. F. Pukall (2019): Picking up good vibrations: Discrepant vibrator use, sexual functioning, and sexual well-being in women with male partners, Psychology \& Sexuality, DOI: 10.1080/19419899.2019.1679230

To link to this article: https://doi.org/10.1080/19419899.2019.1679230

Accepted author version posted online: 09

Oct 2019

Submit your article to this journal $\sqsubset$

Q View related articles ๘

View Crossmark data $\complement$ 
Publisher: Taylor \& Francis \& Informa UK Limited, trading as Taylor \& Francis Group

Journal: Psychology \& Sexuality

DOI: $10.1080 / 19419899.2019 .1679230$

Picking up good vibrations: Discrepant vibrator use, sexual functioning, and sexual well-being in women with male partners

Gauvin, S., ${ }^{a}$ Yessick, L., ${ }^{a}$ and Pukall, C. F. ${ }^{a^{*}}$

${ }^{*}$ Corresponding Author

${ }^{a}$ Department of Psychology, Queen's University, Kingston, Canada,

Stéphanie Gauvin

Address: Department of Psychology, Queen's University, Kingston, Ontario, Canada, K7L 3N6

Phone: 1-855-433-3276; Email: 12SG78@queensu.ca

Lindsey Yessick

Address: Department of Psychology, Queen's University, Kingston, Ontario, Canada, K7L 3N6

Phone: 1-855-433-3276; Email: lindsey.yessick@queensu.ca

Caroline F. Pukall, PhD, CPsych

Address: Department of Psychology, Queen's University, Kingston, Ontario, Canada, K7L 3N6

Phone: 1-613-533-3200; Email: caroline.pukall@queensu.ca

Socia media: http://sexlab.ca;@QSexLab; http://www.facebook.com/sexlab.ca

Stéphanie Gauvin is a Clinical Psychology doctoral student under the supervision of Dr. Caroline Pukall in the Sexual Health Research Laboratory (SexLab) at Queen's University. Stéphanie's 
research focuses on how couples negotiate and navigate sexual challenges, with a focus on how sexual script flexibility is related to sexual well-being.

Lindsey Yessick is a doctoral student in Cognitive Neuroscience Psychology under the cosupervision of Dr. Caroline Pukall and Dr. Tim Salomons in the Pain, Affect, and Cognition Laboratory at Queen's University. Lindsey's research focuses on pain processing in women with provoked vestibulodynia.

Dr. Caroline Pukall received her Ph.D. in Clinical Psychology from McGill University. She is currently a Professor in the Department of Psychology, Director of the Sexual Health Research Laboratory (SexLab), and the Director of the Sex Therapy Service at the Psychology Clinic at Queen's University. 


\title{
Picking up good vibrations: Discrepant vibrator use, sexual functioning, and sexual well-being in women with male partners
}

\author{
Gauvin, S., Yessick, L., \& Pukall, C.
}

Vibrator use is thought to be associated with positive sexual functioning for women with female or male partners (Herbenick et al., 2009). Vibrator use that is discrepant across contexts (i.e., discrepant vibrator use means that the individual uses a vibrator in solitary but not partnered contexts), however, has only been examined in women who have female partners. Results indicate that women who were discrepant reported lower sexual functioning scores than women who were non-discrepant (i.e., those who use a vibrator in both solitary and partnered contexts) (Schick et al., 2011). The current study sought to examine if discrepant vibrator use was related to sexual functioning and global sexual well-being in women with male partners. A total of 488 women with male partners completed online measures of sexual function, sexual satisfaction, and the perceived balance of sexual rewards to costs (i.e., how preferred aspects of the sexual relationship are greater or less than non-preferred aspects). There were no observed differences across the groups of women who reported discrepant, non-discrepant, or no vibrator use on any of the sexual functioning measures. Women with non-discrepant vibrator use reported greater sexual satisfaction than those who were discrepant, and they also reported a greater balance of sexual rewards to costs relative to women with discrepant or no vibrator use. The results of this study suggest that discrepant vibrator use is not related to sexual functioning but is related to sexual well-being in women with male partners.

Keywords: vibrator use, discrepancy, sexual scripts, sexual functioning, sexual well-being 


\section{Introduction}

"What is sex?" The answer to this question likely depends on whom you ask. Individuals differ in how they define sex; these definitions are known as sexual scripts (Simon \& Gagnon, 1984). Sexual scripts act as guides and are developed at three interactive levels: the individual (intrapersonal), the relational (interpersonal), and societal (cultural; Gagnon \& Simon, 1987; Simon \& Gagnon, 1984, 1986; for examples of the three levels, see Gauvin \& Pukall, 2018). Sexual scripts influence what does and does not constitute a sexual experience - they cover the who, what, when, where, and how of sex (Gagnon, 1990). Sexual scripts can be thought of as 'menus' of sexual acts that the individual or couple can select from during sexual activity. Each member of the couple has their own sexual preferences and, through shared interactions, the couple integrates and negotiates the individual preferences of both members to create a mutual or shared 'menu' of sexual activities.

Sex toys and pleasure enhancers are common menu items, as they are becoming immensely popular and more often incorporated into the sex lives of individuals and couples. Vibrator use in the United States, for example, is common, with $52.5 \%(n \approx 1079$ out of $N=$ $2,056)$ of women aged $18-60$ years in a nationally representative sample reporting vibrator use during sexual activity at least once in their lifetime (Herbenick et al., 2009). Although a large portion of women use vibrators during solitary sexual activity $(46.3 \% ; n \approx 937)$, a smaller percentage of women $(40.9 \% ; n \approx 826)$ report using a vibrator during partnered sexual activity (Herbenick et al., 2009). These results suggest that some partnered women may use vibrators exclusively by themselves, and never with their partner (i.e., are discrepant in their vibrator use). For the current study, discrepant vibrator use indicates the individual uses a vibrator in solitary but not partnered contexts and non-discrepant vibrator use indicates the individual uses a vibrator in both solitary and partnered contexts. 
Although research has not examined this question, partnered women could be discrepant in their vibrator use for a multitude of reasons. It is possible that, for some couples, discrepant use may be related to differences in sexual preferences. For example, some couples may have discussed their sexual preferences, and one (or both) member of the couple did not want to include vibrators in their shared 'menu' of sexual activities. Alternatively, some women may have concerns about their partners' reactions to vibrator use and may not feel comfortable disclosing their desire for vibrator use. Indeed, in a subsample from the same national probability sample mentioned above of Americans aged 18-60 years, a large majority of women who use vibrators reported that they were comfortable using a vibrator by themselves $(85.0 \% ; n=889$ out of 1060 women); however, in a separate question only $69.6 \%(n=730)$ of women said they were comfortable using a vibrator with their partner (Herbenick et al., 2010). Although a large majority of women reported comfort in vibrator use overall, differences in their use and perception of vibrators were observed based on sexual orientation. Reported reasons for why bisexual and heterosexual women were uncomfortable telling their partner about their solitary vibrator use included being too embarrassed to tell their partner or worrying that they may insult him or hurt his feelings. These worries were not unfounded, several women had been told by their partners that solitary masturbation and vibrator use would "make him feel less of a man" (Herbenick et al., 2010, p. 58). Interestingly, attitudes toward vibrators appear to differ by sexual orientation. Although $100 \%(n=26)$ of the lesbian women in this sample reported feeling comfortable using a vibrator with a partner, only $68.5 \%(n=252)$ of the heterosexual women reported feeling comfortable (Herbenick et al., 2010). Lesbian women tended to describe sex toys as 'fun and subversive', whereas heterosexual women tended to describe sex toys with shame or as a threat to their male partners (Fahs \& Swank, 2013). The hesitancy that some 
women with male partners experience in incorporating vibrators into their partnered interactions is important, because they may be missing out on a potential to enhance their sexual experiences. Indeed, sex therapists and educators have long proposed the therapeutic utility of vibrators in enhancing sexual pleasure (Heiman, LoPiccolo, \& Piccolo, 2010; Marcus, 2011).

Consistent with sex therapist and educator recommendations, approximately one-third of women in the nationally representative American study mentioned above ( $n=342$ out of $N=$ 1070) reported they used vibrators to facilitate orgasm (Herbenick et al., 2010). Indeed, heterosexual women who had ever used a vibrator in either a solitary or partnered context reported more positive sexual functioning on the desire, arousal, lubrication and pain subscales of the Female Sexual Function Index (FSFI; Rosen, 2000; Herbenick et al., 2010). In comparison, lesbian women who had ever used a vibrator in either a solitary or partnered context only showed significantly greater scores on the orgasm and satisfaction subscales of the FSFI than women who had never used a vibrator in either context (Herbenick et al., 2010). Collectively, these results highlight the potential enhancing effect of vibrators on sexual functioning and satisfaction when used in either a solitary or partnered context. However, is the positive relationship between vibrator use and sexual functioning and satisfaction maintained when vibrator use is not consistent across contexts (i.e., is discrepant)?

Research investigating discrepant vibrator use in a cross-sectional sample of women with female partners $(n=2,192)$ in the United States and the United Kingdom found that women who had used a vibrator in the previous month in both a solitary and partnered context fared better on domains of sexual functioning than participants with no history of vibrator use or only vibrator use in a solitary context (Schick et al., 2011). These results, however, have not been replicated in a sample of women with male partners or in a sample outside of the United States of America. 
Given differences in the comfort levels of disclosing vibrator use with partners between heterosexual women and lesbian women (Herbenick et al., 2010), it is possible that this pattern of results may not generalize to women with male partners.

\section{Current Study}

The objective of this study was to examine potential differences in sexual functioning and global sexual well-being across women with male partners who are discrepant in their vibrator use (use exclusively by themselves), not discrepant in their vibrator use (use vibrators by themselves and with their partners), or do not use vibrators. In the current study, global sexual well-being encompasses sexual satisfaction and a greater balance of sexual rewards (preferred aspects of sexual interactions) to sexual costs (non-preferred aspects of sexual interactions). Consistent with research examining discrepant vibrator use in women with female partners, we predicted that those who were not discrepant in their vibrator use would have greater sexual functioning across the domains of desire, arousal, pain, and orgasm than those who are discrepant in their vibrator use. We also predicted that those who are not discrepant in their vibrator use would have greater global sexual well-being than those who are discrepant in their vibrator use.

\section{Method}

\section{Participants}

A total of 488 women were recruited to complete an online survey. Eligibility criteria for recruitment included being (i) at least 18 years of age, (ii) in an intimate relationship lasting at least three months, and (iii) a women with a male partner. Participants were a mean age of 25.74 years old $(S D=6.91)$. Table 1 contains demographic characteristics for the sample and Figure 1 contains a flow chart for participant recruitment.

\section{Procedure}


Participant recruitment took place through advertisements posted on social media (e.g., Facebook, Reddit, Twitter), which were both posted and shared through the investigators' lab social media accounts and posted in groups and/or subreddits, and relevant listservs (e.g., Pride groups, university listservs, sexual health centers). These posts indicated that we were recruiting participants in intimate romantic relationships (dating for a minimum of three months) with or without sexual problems/concerns for an online study on sexual well-being. The majority $(n=$ 354) of the sample were recruited through Reddit and the remainder were through other social media platforms. Participants were directed from the study advertisements to a letter of information and consent form prior to responding to the survey, which was hosted through the Checkbox Survey website (Checkbox Survey Inc., Watertown, MA). The current study was part of a larger survey which took approximately 30-45 minutes to complete. Participants were then given the option to provide their email address to be entered into a prize draw to possibly win one of four $\$ 50 \mathrm{CAD}$ cash prizes.

\section{Measures}

Demographics. Participants first responded to demographic information including age, sexual orientation, relationship status, birthplace, ethnicity, education, and income.

Discrepant vibrator use. Participants were categorized into four groups based on their vibrator use in solitary and partnered sexual contexts. Participants were presented with a list of sexual enhancers that individuals may use during solo (i.e., masturbation) or coupled (with a partner) sexual activities. For external vibrators, participants were asked to indicate if they have ever used an external vibrator by themselves, with a partner, or both. For the current study, participants were then separated into groups for analysis representing their external vibrator use: non-discrepant vibrator use (i.e., used in both solo and partnered contexts), discrepant vibrator use (used only in solo contexts), or no vibrator use. 
Female Sexual Function Index (FSFI; Rosen, 2000). To assess sexual functioning, participants completed the FSFI. The FSFI is a 19-item scale that asks about sexual feelings and responses during the past four weeks and yields domain scores in six areas: sexual desire, arousal, lubrication, orgasm, satisfaction, and pain. Participants responded on Likert-type scales with varying anchors from 0 to 5 (with the exception of the desire subscale which ranged from 1 to 5) to questions such as, "Over the past 4 weeks, how often did you feel sexual desire or interest?". Subscale scores were calculated by taking the average across subscale items. The subscales of the FSFI have excellent internal reliability (Cronbach's alphas $>.90$ for all subscales) and good test-retest reliability (scores from .79 to .88). For the present study, subscales of sexual desire, arousal, lubrication, orgasm and pain were used with Cronbach's alpha values ranging from .85 to .90 (good-excellent range) for all subscales. The current study did not administer the satisfaction subscale, because satisfaction was assessed using the Global Measure of Sexual Satisfaction (see below).

Global Measure of Sexual Satisfaction (GMSEX; Lawrance \& Byers, 1995; Lawrance, Byers, \& Cohen, 2019). The GMSEX measures satisfaction in one's sexual relationship. Participants responded to the question of: "Overall, how would you describe your sexual relationship with your partner?" using five 7-point scales with different descriptive adjectives at each anchor (e.g., Very Bad - Very Good; Worthless - Very Valuable). Total scores were calculated by summing all items, with possible scores ranging from 5 to 35 . Higher scores on the GMSEX indicate greater satisfaction in one's sexual relationship. It has been shown that the GMSEX is significantly correlated with other measures of sexual satisfaction, such as the Index of Sexual Satisfaction (ISS; Hudson, Harrison, \& Crosscup, 1981), the New Sexual Satisfaction Scale-Short (NSSS-S; Stulhofer, Busko, \& Brouillard, 2010) and other indicators of sexual/relationship functioning, including frequency of sex, sexual desire, sexual 
communication, sexual esteem, and sexual cognitions (Lawrance, Byers, \& Cohen, 2019). The GMSEX received the strongest psychometric support as a measure of sexual satisfaction when its scale score reliability, test-retest reliability, convergent validity, and factor structure were compared to the Index of Sexual Satisfaction (Hudson et al., 1981), the New Sexual Satisfaction Scale - Short (NSSS-S; Štulhofer, Buško, \& Brouillard, 2010), and a single item question of sexual satisfaction (Mark et al., 2014). The GMSEX scores have high scale score reliability $(\alpha>$ $.90)$ and test-retest reliability at 3-month $(r>.70)$ and 18-month intervals $(\alpha>.61)$ (Byers et al., 1998; Byers \& MacNeil, 2006). Cronbach's alpha in the present study was $\alpha=.96,95 \% \mathrm{CI}$ [0.955, 0.966] (excellent range).

Sexual Exchanges Questionnaire (SEQ; Lawrance et al., 2011). The SEQ is a six-item self-report questionnaire that assesses sexual rewards and costs across three components: the balance of sexual rewards and costs in the current relationship; the perceived equality between sexual partners; and the balance between the levels of received rewards and costs versus the levels of expected rewards and costs. For the present study, only items assessing the balance of sexual rewards and costs in the current relationship were used. Participants indicated how rewarding and how costly they perceive their current sexual relationship. On two separate 9point Likert scales from 'not at all' to 'extremely', participants indicated how rewarding and how costly they perceive their current sexual relationship to be. A balance of sexual rewards to costs was calculated by subtracting the level of sexual costs from sexual rewards (Rew-Cst) so that possible scores ranged from -8 to 8 , with higher scores indicating a more favorable balance of rewards to costs. Rew-Cst has been found to predict sexual satisfaction among individuals in dating and long-term relationships (e.g., Byers \& Demmons, 1999; Lawrance \& Byers, 1995). 
The Dyadic Sexual Communication Scale (DSCS; Catania, 2011). The DSCS is a 13item measure of sexual communication. Participants responded using a scale from 1 'disagree strongly' to 6 'agree strongly' to questions such as, "My partner rarely responds when I want to talk about our sex life". Total scores were calculated by summing all items, with scores ranging from 13 to 78. Higher scores indicate better quality of dyadic sexual communication. The DSCS has been shown to have good scale score reliability $(\alpha=.81)$ and is capable of differentiating between individuals who experience sexual difficulties and those who do not (Catania, 2013). Cronbach's alpha in the present study was $\alpha=.89,95 \%$ CI $[0.868,0.900]$ (excellent range).

\section{Results}

\section{Participant Characteristics}

A summary of participant sociodemographic characteristics can be found in Table 1 . The average age of participants was 25.74 years $(S D=6.91)$ and the average relationship length was 59.05 months $(S D=54.81)$. Most participants were from Canada $(25.1 \%)$ or the United States $(50.5 \%)$ and a majority had some form of post-secondary education (91.4\%). Participants were divided into four groups for analyses: non-discrepant vibrator use in the $\mathrm{S} / \mathrm{P}$ (solo vibrator use/partnered vibrator use; $n=187$ ) group, discrepant vibrator use in the $\mathrm{S}$ (solo vibrator use/no partnered vibrator use; $n=83$ ) group, and no vibrator use in the $\mathrm{N}$ (no solo vibrator use/no partnered vibrator use; $n=198$ ) group. Due to the small sample, we excluded the group with no solo vibrator use/partnered vibrator use $(n=20)$.

\section{Vibrator Use Context and Sexual Functioning}

The association between discrepant vibrator use and sexual functioning was assessed by comparing the domains of sexual functioning across vibrator use context using one-way Analysis of Variance (ANOVA) with Bonferroni corrections for follow-up $t$-test comparisons (see Table 2). For all ANOVAs, Levene's test for homogeneity of variance was not significant, indicating 
that the assumption of homogeneity of variance was not violated. There were no statistically significant differences across vibrator use context for any subscale of sexual functioning (sexual desire, arousal, orgasm, lubrication, and pain).

\section{Vibrator Use Context and Global Sexual Well-being}

We assessed differences across vibrator use context for sexual satisfaction and the sexual rewards to costs ratio using one-way ANOVAs with Bonferroni corrections for follow-up $t$-test comparisons (see Table 2). For both ANOVAs, Levene's test for homogeneity of variance was not significant, indicating that the assumption of homogeneity of variance was not violated. There was a statistically significant difference across vibrator context for sexual satisfaction $\left(F(2,462)=5.72, p=.009, \eta p^{2}=.020\right)$, with individuals who reported using vibrators in both contexts $(\mathrm{S} / \mathrm{P} ; M=25.88, S D=5.49)$ having greater sexual satisfaction scores than individuals who reported only using a vibrator in a solitary context $(S ; M=23.52, S D=7.20 ; t(268)=2.35$, $p=.027$, Cohen's $d=0.37$ ). There was also a statistically significant difference across vibrator use context for the rewards to cost ratio, $F(2,462)=8.37, p<.001, \eta p^{2}=.035$. Specifically, individuals who reported using a vibrator in both solitary and partnered contexts $(\mathrm{S} / \mathrm{P} ; M=3.92$, $S D=2.40)$ reported a significantly greater rewards to cost ratio than individuals who reported using a vibrator only in a solitary context $(\mathrm{S} ; M=2.67, S D=2.88 ; t(268)=1.25, p=.003$, Cohen's $d=0.47)$, and individuals who reported no vibrator use in either context $(\mathrm{N} ; M=3.00$, $S D=2.89 ; t(391)=.92473, p=.005$, Cohen's $d=0.35)$.

\section{Exploratory Analyses of Vibrator Use Context and Sexual Communication}

The association between discrepant use and sexual communication was assessed post-hoc by comparing the measure of sexual communication across vibrator use context using one-way ANOVAS with Bonferroni corrections for follow-up $t$-test comparisons (see Table 3). Levene's test for homogeneity of variance was not significant, indicating that the assumption of 
homogeneity of variance was not violated. There was a statistically significant difference across vibrator context for sexual communication $\left(F(2,452)=12.68 p<.001, \eta p^{2}=.053\right)$, with individuals who reported using vibrators in both contexts $(\mathrm{S} / \mathrm{P} ; M=66.31, S D=10.98)$ having higher sexual communication scores (i.e. higher sexual communication) than individuals who reported only solitary vibrator use $(\mathrm{S} ; M=58.53, S D=13.81 ; \mathrm{t}(263)=7.78, p<.001$; Cohen's $d$ $=0.62)$ and individuals who reported no vibrator use in either context $(\mathrm{N} ; M=62.09, S D=$ $12.62 ; t(371)=4.22, p=.005 ;$ Cohen's $d=0.36)$.

\section{Discussion}

The present study sought to examine if a discrepancy between solitary and partnered vibrator use context (i.e., the individual uses a vibrator exclusively in solitary but not partnered contexts) is related to sexual functioning and global sexual well-being outcomes in women with male partners. We hypothesized that those who were discrepant between the contexts of vibrator use would have lower sexual functioning and global sexual well-being scores than those who were not discrepant. Surprisingly, there were no statistically significant differences across vibrator use context and any domain of sexual functioning. However, women who used vibrators in both contexts reported greater sexual satisfaction than those who were discrepant; they also reported a greater reward to cost ratio score than women who reported discrepant use and women who never used a vibrator in either context.

The lack of statistically significant differences across vibrator use context for sexual functioning is surprising when contrasting this finding to previous results in women with women partners (Schick et al., 2011) and women who are "ever" versus "never" users of vibrators (Herbenick et al., 2010). Specifically, we would have expected there to be significant differences in the functioning domains of desire, arousal, pain, and orgasm. It is possible that the contrasting results found between previous research and the current study reflect differences between the 
sample characteristics and methodologies. For example, Schick et al. (2011) included 2,192 female participants from the United States and the United Kingdom in their sample, and Herbenick et al., (2009; 2010) included 2,056 participants from the United States. In the current study, we included 488 women from different countries (e.g., Canada, European countries). Furthermore, in the current study, we asked if they have ever used a vibrator with their current partner, whereas Schick and colleagues asked about partnered vibrator use in the last month - the same timeframe used by the Female Sexual Function Index (FSFI; Rosen et al., 2000). It may be that not having the same reflection timeframe for both the FSFI (Rosen et al., 2000) and vibrator use results in more measurement error in the data, thus increasing the likelihood of a type II error (i.e., when one fails to reject a null hypothesis that is actually false; a false negative). Differences such as these may have impacted the ability to detect small effect sizes, such as those found in the current study ( $\eta p^{2} .001-.035$ for sexual functioning domains).

It is also possible that the differences between the current study and Schick et al. (2011) reflect true differences between women in same- versus mixed-gender relationships in the association between vibrator use context and sexual functioning. It is unlikely that there are physiological differences between women in same- versus mixed-gender relationships that would contribute to differing sexual functioning (e.g., solitary activity orgasm rates do not differ between groups; Blair, Cappell, \& Pukall, 2018). However, differences in partnered experiences may play a role in aspects of sexual functioning (e.g., relationship type has an effect on orgasm rates; Blair et al., 2018). As such, it is more likely that the differences in the pattern of the results between the current study and Schick et al. (2011) are related to partnered experiences rather than physiological differences. The differences in the pattern of results could reflect true differences between women in same- versus mixed-gender relationships, however, there is a 
growing body of research that suggests there are more similarities than differences in subjective sexual experiences (i.e., a person's individual experiences of sexual activity) between samegender and mixed-gender relationships (Holmberg \& Blair, 2010; Gauvin \& Pukall, in preparation). Further research is needed to explore the similarities and differences in the sexual functioning and subjective sexual experiences of women in same- and mixed-gender relationships. Given that many measures are developed and validated in heterosexual populations and may not fully capture the experiences of sexually diverse individuals, future research should adopt a mixed-methods approach (e.g., include both qualitative and quantitative methods).

Interestingly, we found differences in global sexual well-being across vibrator use context. Specifically, individuals who use vibrators both by themselves and with a partner reported greater sexual satisfaction and a greater level of sexual rewards to costs than individuals who use vibrators by themselves but not with a partner. Although this pattern of results may be surprising given the lack of significant differences in the various domains of sexual functioning assessed in this study, it is important to note that sexual function scores do not necessarily predict sexual satisfaction scores. For instance, if individuals find using a vibrator pleasurable, we could speculate that discrepant use - although not associated with sexual functioning per seis associated with lower levels of pleasure experienced during partnered sexual interactions. In other words, discrepant vibrator use may not result in being less 'turned on' (i.e., lower arousal) but may result in less physical pleasure. As such, non-discrepant vibrator use may increase the pleasure experienced, which may in turn, be associated with increased sexual satisfaction. Although not assessed in the current study, it is possible that individual factors - such as erotophilia (i.e., the propensity to respond to sexual cues; Fisher, White, Byrne, \& Kelley, 1988), sex positivity (i.e., communities' and individuals' openness, nonjudgment, and flexibility and 
sexual preferences; Donaghue, 2015), and self-perceived sexual attractiveness (i.e., feeling sexually desirable and valuable to others; Amos \& McCabe, 2017)—may account for some of the differences in sexual satisfaction across vibrator use context. Alternatively, discrepancy in vibrator use across contexts might reflect more global sexual relationship differences related to sexual well-being, such as differences in the amount of sexual communication in which these couples engage. Indeed, our exploratory follow-up analyses suggested that sexual communication was also different across vibrator use context. Individuals who reported using vibrators in both contexts had higher sexual communication than individuals who reported only solitary vibrator use. Schick et al. (2011) proposed that women who use vibrators with a partner may be more sexually assertive about their sexual preferences. It is possible that sexual assertiveness and communication may allow individuals to disclose what sexual activities are pleasurable for them and better facilitate the negotiation of a mutual or shared 'menu' of sexual activities that incorporates more satisfying or preferred activities. Indeed, the instrumental pathway (MacNeil \& Byers, 2005) proposes that sexual self-disclosures allow partners to better understand sexual rewards and costs, and that understanding increases the likelihood of partners responding in a way that enhances pleasure. Alternatively, MacNeil and Byers (2005) also found some support for the expressive pathway of sexual self-disclosures with women, wherein selfdisclosures lead to greater feelings of intimacy and relationship satisfaction which, in turn, promoted higher levels of sexual satisfaction. It may also be that women who are not discrepant in their vibrator use are communicating more and that communicating sexual preferences promotes feelings of intimacy and closeness with their partner, which in turn contributes to greater sexual satisfaction. Indeed, communication and partner responses appear to be of important concern to women who do not disclose their vibrator use to their partner. Research 
with heterosexual women who have ever used a vibrator found that $14.1 \%(n=49)$ had never told their partner about their vibrator use (Herbenick et al., 2010). Among women who did not disclose their vibrator use to their partner, expectations of "positive reactions from a partner" were rare (Herbenick et al., 2010). Women commonly reported concerns of making their partner feel inadequate, hurting their feelings, being too embarrassed and/or uncomfortable with disclosure. As such, discomfort with communicating about sexual preferences with a partner would likely be a barrier to incorporating sexual preferences into partnered interactions. Future research with a priori hypotheses are needed to clarify the association between vibrator use context and sexual well-being and to explore sexual communication as a potential mediator in this association.

\section{Limitations and future directions}

Due to the cross-sectional design of this study, caution should be used when interpreting and generalizing the results. Future studies should consider using longitudinal designs (e.g., daily diaries) of individuals who use vibrators with a partner and examine whether satisfaction/well-being differ across interactions where a vibrator is or is not incorporated.

Although our results provided support to the hypothesis that non-discrepant vibrator use is related to better sexual well-being, we have no way of knowing if there are nuanced differences wherein discrepant use may relate to better sexual well-being. For example, some women may have communicated with their male partner about vibrator use and decided that they did not want to use a vibrator. In addition, there may be differences between women who did or did not want to incorporate vibrators into their partnered sexual interactions. Future research should seek to understand how communication around vibrator use and reasons for choosing not to use a vibrator in a partnered context can influence the association between discrepant vibrator use and sexual well-being. 
Finally, in the current study, the frequency of vibrator use in each context was not queried; instead, participants were asked if they had ever used a vibrator by themselves or with their current partner. As previously mentioned, querying about ever use resulted in participants reflecting on a different timeframe for vibrator use than sexual functioning and sexual satisfaction (i.e., past 4 weeks). Furthermore, due to this restrictive question, we do not have a sense of how central vibrator use is for an individual's or a couple's sexual script. For instance, our sample may include people who have only experimented with vibrator use a single time by themselves or with a partner, and individuals who may or may not have found it pleasurable. As such, we have no way of assessing how frequency of vibrator use is related to sexual well-being. Future research should investigate whether the frequency of and satisfaction with vibrator use mediates the association between discrepant vibrator use and sexual well-being. Beyond the frequency of vibrator use, the present study also only examined discrepancies in vibrator use, so it is unclear if these findings would generalize to other sex toys (e.g., butt plugs, dildos, nipple stimulators). Future research should examine whether discrepancies in the use of other sex toys across contexts are also related to sexual well-being outcomes.

\section{Implications and Conclusions}

The pattern of results found in the current study suggest that vibrator use context is related to broader sexual well-being but not sexual functioning domains. Women with nondiscrepant vibrator use reported greater sexual satisfaction and rewards-to-costs ratios than women with discrepant use. No significant differences were found in the association between vibrator use context and domains of sexual functioning. Exploratory follow-up analyses of differences in sexual communication scores across discrepant and non-discrepant use suggest differences in sexual communication that may provide insight into the mechanisms accounting for these results. While clinicians have long recognized the benefits of integrating vibrator use 
into solitary sexual activity (Marcus 2011; Riley \& Riley, 1978; LoPiccolo \& Lobitz, 1972; Brotto et al., 2008), the association of partnered vibrator use with sexual well-being has been largely unexplored in the literature and may be relevant to sex therapists making recommendations in therapy. The results of the current study provide evidence that asking about both solitary and partnered vibrator use may be important, because discrepancies between these contexts were related to sexual well-being as indicated by lower sexual satisfaction and a lower balance of sexual rewards to costs. As these results are correlational, it is possible that many other factors may account for the relationship between vibrator use contexts and sexual wellbeing variables, including dyadic relationship variables (e.g., communication) and/or individual factors (e.g., erotophilia). However, the results of this study suggest that promoting the incorporation of a vibrator into solitary and partnered sexual activity could potentially contribute to the experience of more sexual rewards relative to costs.

\section{References}

Amos, N., \& McCabe, M. (2017). The importance of feeling sexually attractive: Can it predict an individual's experience of their sexuality and sexual relationships across gender and sexual orientation?. International Journal of Psychology, 52(5), 354-363.

Blair, K. L., Cappell, J., \& Pukall, C. F. (2018). Not all orgasms were created equal: Differences in frequency and satisfaction of orgasm experiences by sexual activity in same-sex versus mixed-sex relationships. The Journal of Sex Research, 55(6), 719-733.

Brotto, L. A., Heiman, J. R., Goff, B., Greer, B., Lentz, G. M., Swisher, E., ... \& Van Blaricom, A. (2008). A psychoeducational intervention for sexual dysfunction in women with gynecologic cancer. Archives of Sexual behavior, 37(2), 317-329. 
Byers, E. S., \& Demmons, S. (1999). Sexual satisfaction and sexual self-disclosure within dating relationships. Journal of Sex Research, 36(2), 180-189. doi:10.1080/00224499909551983

Byers, E. S., Demmons, S., \& Lawrance, K. A. (1998). Sexual satisfaction within dating relationships: A test of the interpersonal exchange model of sexual satisfaction. Journal of Social and Personal Relationships, 15(2), 257-267. http:

//doi.org/10.1177/0265407598152008

Byers, E. S., \& MacNeil, S. (2006). Further validation of the interpersonal exchange model of sexual satisfaction. Journal of Sex \& Marital Therapy, 32(1), 53-69. doi:10.1080/00926230500232917

Catania, J. A. (2011). The Dyadic Sexual Communication Scale. In T. D. Fisher, C. M. Davis, W. L. Yarber, \& S. L. Davis (Eds.), Handbook of sexuality related measures (3rd ed., pp. 130-132). New York, NY: Routledge.

de Visser, R. O., Smith, A. M., Rissel, C. E., Richters, J., \& Grulich, A. E. (2003). Sex in Australia: Heterosexual experience and recent heterosexual encounters among a representative sample of adults. Australian and New Zealand Journal of Public Health, 27(2), 146-154.

Donaghue, C. (2015). Sex outside the lines: Authentic sexuality in a sexually dysfunctional culture. Benbella Books Dallas, Texas.

Gagnon, J. H. (1990). The explicit and implicit use of the scripting perspective in sex research. Annual Review of Sex Research, 1(1), 1-43. 
Gauvin, S., \& Pukall, C. F. (2018). Sexual problems and sexual scripts: Overview and future directions for bisexual-identified individuals. Sexual and Relationship Therapy, 33(1-2), $34-44$.

Fahs, B., \& Swank, E. (2013). Adventures with the "Plastic Man": Sex toys, compulsory heterosexuality, and the politics of women's sexual pleasure. Sexuality \& Culture, 17(4), $666-685$.

Fisher, W. A., White, L. A., Byrne, D., \& Kelley, K. (1988). Erotophobia erotophilia as a dimension of personality. Journal of Sex Research, 25(1), 123-151.

Heiman, J. R., LoPiccolo, J., \& Piccolo, L. L. (2010). Becoming orgasmic: A sexual and personal growth programme for women. Prentice Hall Hachette UK.

Herbenick, D., Reece, M., Sanders, S. A., Dodge, B., Ghassemi, A., \& Fortenberry, J. D. (2010). Women's vibrator use in sexual partnerships: Results from a nationally representative survey in the United States. Journal of Sex \& Marital Therapy, 36(1), 49-65.

Herbenick, D., Reece, M., Sanders, S., Dodge, B., Ghassemi, A., \& Fortenberry, J. D. (2009). Prevalence and characteristics of vibrator use by women in the United States: Results from a nationally representative study. The Journal of Sexual Medicine, 6(7), 1857-1866.

Holmberg, D., Blair, K. L., \& Phillips, M. (2010). Women's sexual satisfaction as a predictor of well-being in same-sex versus mixed-sex relationships. Journal of Sex Research, 47(1), $1-11$.

Hudson, W. W., Harrison, D. F., \& Crosscup, P. C. (1981). A short-form scale to measure sexual discord in dyadic relationships. The Journal of Sex Research, 17(2), 157-174. 
Laumann, E. O., Gagnon, J. H., Michael, R. T., \& Michaels, S (1994). The social organization of sexuality: Sexual practices in the United States. University of Chicago Press, Chicago, IL.

Lawrance, K. A., Byers, E. S., \& Cohen, J. N. (2019). Interpersonal Exchange Model of Sexual Satisfaction (pp. 525-526). In Milhausen, R. R., Sakaluk, J. K., Fisher, T. D., Davis, C. M., \& Yarber, W. L. (Eds.) Handbook of Sexuality-Related Measures, $4^{\text {th }}$ ed (p. 497503). Routledge, UK.

Lawrance, K. A., \& Byers, E. S. (1995). Sexual satisfaction in long-term heterosexual relationships: The interpersonal exchange model of sexual satisfaction. Personal Relationships, 2(4), 267-285. doi:10.1111/j.1475-6811.1995.tb00092.x

LoPiccolo, J., \& Lobitz, W. C. (1972). The role of masturbation in the treatment of orgasmic dysfunction. Archives of Sexual Behavior, 2(2), 163-171.

MacNeil, S., \& Byers, E. S. (2005). Dyadic assessment of sexual self-disclosure and sexual satisfaction in heterosexual dating couples. Journal of Social and Personal Relationships, 22(2), 169-181.

Marcus, B. S. (2011). Changes in a woman's sexual experience and expectations following the introduction of electric vibrator assistance. The Journal of Sexual Medicine, 8(12), 33983406.

Mark, K. P., Herbenick, D., Fortenberry, J. D., Sanders, S., \& Reece, M. (2014). A psychometric comparison of three scales and a single-item measure to assess sexual satisfaction. Journal of Sex Research, 51(2), 159-169.

doi:10.1080/00224499.2013.816261 
Riley, A. J., \& Riley, E. J. (1978). A controlled study to evaluate directed masturbation in the management of primary orgasmic failure in women. The British Journal of Psychiatry, 133(5), 404-409.

Rosen, C. Brown, J. Heiman, S. Leiblum, C. Meston, R. Shabsigh, D. Ferguson, R. D'Agostino, R. (2000). The Female Sexual Function Index (FSFI): A multidimensional self-report instrument for the assessment of female sexual function. Journal of Sex \& Marital Therapy, 26(2), 191-208.

Schick, V., Herbenick, D., Rosenberger, J. G., \& Reece, M. (2011). Prevalence and characteristics of vibrator use among women who have sex with women. The Journal of Sexual Medicine, 8(12), 3306-3315.

Simon, W., \& Gagnon, J. H. (1984). Sexual scripts. Society, 22(1), 53-60.

Štulhofer, A., Buško, V., \& Brouillard, P. (2010). Development and bicultural validation of the New Sexual Satisfaction Scale. Journal of Sex Research, 47(4), 257-268. doi:10.1080/00224490903100561

Table 1

Participant demographic information

\begin{tabular}{lc}
\hline & $n=488$ \\
\hline Age in years $(M(S D))$ & $25.74(6.91)$ \\
Sexual Orientation $(n(\%))$ & \\
$\quad$ Asexual & $8(1.6)$ \\
Bisexual & $114(23.4)$ \\
Gay/Lesbian & $2(0.4)$ \\
Heterosexual & $287(58.8)$ \\
Pansexual & $46(9.4)$ \\
Queer & $8(1.6)$
\end{tabular}


Other

Relationship Status (n (\%))

Casually dating

Dating partner (regularly)

Dating partner (long distance)

Living with partner

Married/common law/etc.

Other

Length of Relationship in months $(M(S D))$

Birthplace (n (\%))

Canada

Europe

United States

Other

Ethnicity (n (\%))

African

American

Asian

Canadian

Caribbean

European

French Canadian

Latin/Central America

Mexican

North American Aboriginal

Oceanian

Other

Education ( $n(\%))$

Elementary School (some)

Elementary School (complete)

High school (some)

High school (complete)

Post-secondary (some)

Post-secondary (complete)

Graduate/Professional School

Income $(n(\%))$

$\$ 0-19999$

$\$ 20000-39999$

$\$ 40000-59999$

$\$ 60000-89999$

$\$ 9000+$
$21(4.3)$

$3(0.6)$

$164(33.6)$

$74(15.2)$

$128(26.2)$

$102(20.9)$

$17(3.5)$

$59.05(54.81)$

$121(25.1)$

62 (12.8)

$244(50.5)$

56 (11.6)

7 (1.4)

212 (43.4)

$41(8.4)$

125 (25.6)

$3(0.6)$

198 (40.6)

$17(3.5)$

$15(3.1)$

$12(2.5)$

$11(2.3)$

$31(6.4)$

9 (1.8)

$1(0.2)$

$2(0.4)$

$4(0.8)$

$33(6.8)$

$148(30.3)$

202 (41.4)

96 (19.7)

77 (15.3)

93 (19.1)

75 (15.4)

76 (15.6)

$100(20.5)$

Note. Due to missing data, rounding, and multiple responses, not all percentages add up to 100 . 
Table 2.

Association between vibrator use context and sexual functioning/well-being.

\begin{tabular}{lccccc}
\hline & $\mathrm{S} / \mathrm{P}$ & $\mathrm{S}$ & $\mathrm{N}$ & $F$ & $\eta p^{2}$ \\
\hline Sexual functioning & & & & & \\
$\quad$ Desire & $3.32(1.0)$ & $3.42(1.06)$ & $3.30(1.07)$ & 0.38 & 0.002 \\
Arousal & $4.18(0.91)$ & $4.10(0.89)$ & $4.07(0.98)$ & 0.69 & 0.003 \\
Lubrication & $4.39(0.93)$ & $4.39(0.75)$ & $4.33(0.94)$ & 0.22 & 0.001 \\
Orgasm & $3.87(1.19)$ & $3.59(1.32)$ & $3.63(1.26)$ & 2.19 & 0.010 \\
Pain & $3.48(0.37)$ & $3.45(0.49)$ & $3.49(0.38)$ & 0.36 & 0.002 \\
Sexual well-being & & & & & \\
GMSEX & $25.88(5.49)^{\mathrm{a}}$ & $23.52(7.20)^{\mathrm{a}}$ & $24.39(6.76)$ & $4.72^{* * *}$ & 0.020 \\
REW-CST & $3.92(2.40)^{\mathrm{ab}}$ & $2.67(2.88)^{\mathrm{a}}$ & $3.00(2.89)^{\mathrm{b}}$ & $8.37^{* * * *}$ & 0.035 \\
\hline$*<. \mathbf{0 5} * *<. \mathbf{0 1} * * * \mathbf{0 0 5} * * * * \mathbf{0 0 1}$ & & & &
\end{tabular}

$*<.05 * *<.01 * * *<.005 * * * *<.001$
Note: $\mathrm{S} / \mathrm{P}=$ solo vibrator use/partnered vibrator use; $\mathrm{S}=$ solo vibrator use/no partnered vibrator use; $\mathrm{N}=$ no solo vibrator use/no partnered vibrator use. GMSEX = Global Measure of Sexual Satisfaction; REW-CST $=$ Rewards to Costs. Post hoc tests using Bonferroni corrections for 10 pairwise comparisons were conducted. Entries with the same superscript differ statistically. 
Table 3.

Association between vibrator use context and sexual communication.

\begin{tabular}{|c|c|c|c|c|c|}
\hline & $\mathrm{S} / \mathrm{P}$ & $\mathrm{S}$ & $\mathrm{N}$ & $F$ & $\eta p^{2}$ \\
\hline$D S C S$ & $66.31(10.98)^{\mathrm{ab}}$ & $58.53(13.81)^{\mathrm{a}}$ & $62.09(12.62)^{b}$ & $12.68 * * * *$ & 0.053 \\
\hline
\end{tabular}

Note: $\mathrm{S} / \mathrm{P}=$ solo vibrator use/partnered vibrator use; $\mathrm{S}=$ solo vibrator use/no partnered vibrator use; $\mathrm{N}=$ no solo vibrator use/no partnered vibrator use. DSCS = Dyadic Sexual Communication Scale. Entries with the same superscript differ statistically. 


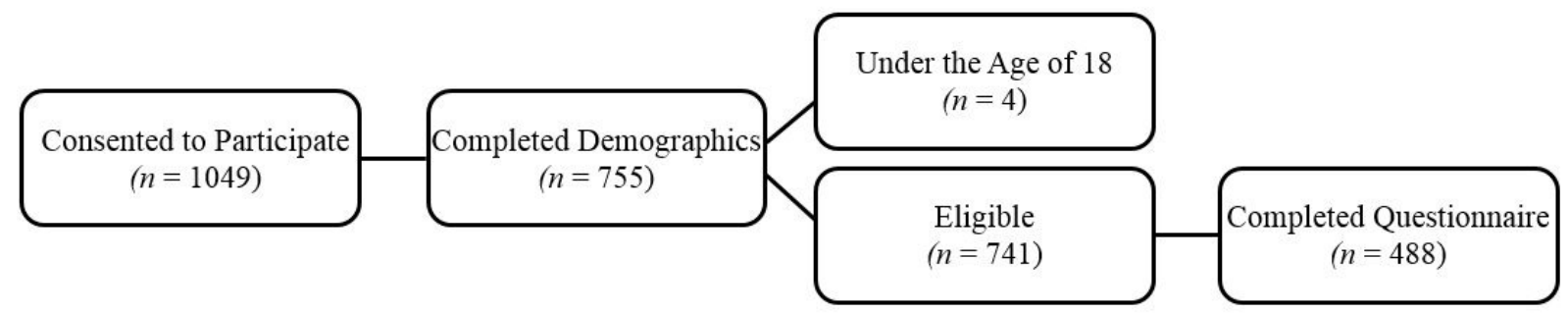

Figure 1. Participant Recruitment Flow Chart 